\title{
Molecular characterization of rotavirus strains causing gastroenteritis in children under 5years in Cairo, Egypt
}

\begin{abstract}
Background: Rotavirus infection has been identified as the most common pathogen associated with acute gastroenteritis in infants and children worldwide.

Objective: This work was designed to study the occurrence of rotavirus among children less than 5years with acute diarrhea admitted to Abu-El Rish hospital in Cairo, Egypt.

Methods: 198 stool specimens were collected during the period from May 2015 to April 2016. The samples were tested for rotavirus by enzyme immunoassays (EIA) them rotavirus-positive specimens were G-genotyped by the semi-nested multiplex reverse transcription polymerase chain reaction (RT-PCR) using different type specific primers.

Results: Out of 198 collected samples rotavirus infection was detected in 56 (28.3\%). Of the rotavirus diarrhea, $64.3 \%$ occurred during the first year of life, with the peak prevalence of severe rotavirus disease in March and April. Among the common genotypes, G3 was the most predominant (17.8\% of strains). Other identified genotypes such as G1, G9, and G10 were detected separately in $5.3 \%$ of the positive samples, whereas G4 was detected in only $1.8 \%$. Furthermore, G2 was not found in this study. The most circulating mixed G types were $\mathrm{G} 1+\mathrm{G} 3+\mathrm{G} 8(17.8 \%)$, followed by $\mathrm{G} 3+\mathrm{G} 9(1.8 \%)$.

Conclusion: The current study demonstrated that rotavirus accounted for $28.3 \%$ of gastroenteritis, particularly among children under lyears of age with a high prevalence of the G3 genotype. Our findings provide useful data for future vaccine development approaches in Egypt.
\end{abstract}

Keywords: rotavirus, gastroenteritis, children, vaccine
Volume 6 Issue 5 - 2017

\author{
Mohamed Shaheen,'Abd El-Daim \\ SE, 'Hosseney EN, ${ }^{2}$ Shoeib AR, 'Ali MA ${ }^{3}$ \\ Department of Water Pollution Research, Egypt \\ ${ }^{2}$ Department of Plant and Microbiology, Egypt \\ ${ }^{3}$ Center of Scientific Excellence for Influenza Viruses, Egypt
}

Correspondence: Mohamed Shaheen, Environmental Virology Laboratory, Department of Water Pollution Research, Environmental Research Division, National Research Center, AlBuhouth Street 12622 Dokki, Giza, Egypt, Tel 002 010167।007I, Emailm_nrc2007@yahoo.com

Received: October 25, 2017 | Published: December 5, 2017

\section{Abbreviations:rotavirus; immunosorbent assay \\ ELISA: enzyme-linked}

\section{Introduction}

Globally, human rotavirus (RV) remains the most common cause of severe diarrhea in children, causing 453,000 deaths per year and proximately 2.4 million hospitalization among children aged less than 5years, with a maximum incidence in the developing countries. ${ }^{1-3}$ Transmissions of RVs occur mainly via fecal-oral contact but it also might be transmitted by respiratory spread. ${ }^{4,5} \mathrm{RV}$ group A is the most cause of viral gastroenteritis in human and at least $27 \mathrm{G}-$ serotypes and $32 \mathrm{P}$-serotypes have been identified. ${ }^{6,7}$ Among them, 12 G-serotypes (G1 to G6, G8 to G12, G22) and 15 P-serotypes $(\mathrm{P}[1]$ to $\mathrm{P}[11], \mathrm{P}[14], \mathrm{P}[19], \mathrm{P}[25])$ have been identified in human. ${ }^{8-11}$ Globally, G1 to G4 and recently G9 are the major G-serotypes in human. Globally uncommon G-serotypes such as G5, G6, G8, and G10 to G12 may be detected regionally. ${ }^{9-11}$ On the other hand, P[4], $\mathrm{P}[6]$ and $\mathrm{P}[8]$ are the most prevalent human $\mathrm{P}-$ serotypes $^{12,13}$ while rare human $\mathrm{P}$-serotypes $\mathrm{P}[9], \mathrm{P}[11]$ and $\mathrm{P}[14]$ are increasingly identified locally in different areas of the world ${ }^{14,15}$ Furthermore, novel RV serotypes can be produced from mixed infection of segmented RV genome. Two oral live attenuated vaccines, pentavalent RotaTeq (Merck and Co.Inc.), consisting of G1-G4 types with P[8], and monovalent Rotarix (GlaxoSmithKline), consisting of G1 with P[8], to prevent RV gastroenteritis are currently licensed in lower middle income countries ${ }^{16}$ and European countries. ${ }^{17}$ In this study, we studied the incidence of RV genotypes among children less than 5years old circulating in Egypt to determine whether the current vaccines cover the most circulating RV among children below 5years old in Egypt.

\section{Materials and Methods}

\section{Collection and preparation of stool specimens}

A total of 198 fecal specimens were collected from children less than 5years old, who were hospitalized and non-hospitalized with diarrhea at the public Abu-El Rish hospital, Cairo, Egypt. Samples were collected and given special codes by the hospital laboratory team. So we don't need ethical approval for this work. The study period was 1year (from the first of May 2015 to the first of April 2016). Approximately $100 \mathrm{mg}$ of each fecal specimen was initially suspended in $1 \mathrm{ml}$ of phosphate-buffered saline $(\mathrm{pH}=7.0)$. After mixing and centrifugation at $4.500 \mathrm{rpm}$ for $10 \mathrm{~min}$ at $4{ }^{\circ} \mathrm{C}$, the supernatant was transferred into new Eppendorf tube then stored in $-80^{\circ} \mathrm{C}$ until examined.

\section{Detection of rotavirus antigen by Enzyme-linked immunosorbent assay (ELISA)}

ELISA method was used for detection of rotavirus antigens in the collected samples. RIDASCREEN ${ }^{\circledR}$ Rotavirus (R-Biopharm, Germany) kit with $100 \mu 1$ of each sample were used to determine the presence of RV antigen. The microwell plates were coated with monoclonal antibodies against the middle layer antigen of RV (VP6) in 
a sandwich type method. The test procedure was performed according the manufacturer's instruction ${ }^{18}$ The specimen was considered positive if the optical density (OD) was higher than the cut off value (OD of the negative control +0.15 ). All specimens were tested in duplicate, and the positive samples for RV were then subjected to viral RNA extraction and semi-nested multiplex RT-PCR tests.

\section{Viral RNA extraction}

RV genome was extracted from $10 \%$ stool suspension of each specimen by QIAamp Viral RNAmini Kit (Qiagen, Germany), according to the protocol described in the manufacturer's guidelines.

\section{Reverse transcription-polymerase chain reaction (RT-PCR)}

cDNA was synthesized in a final volume $25 \mu 1: 5 \mu 1$ of the extracted RNA with $1 \mu 1$ of reverse primer VP7-R $(50 \mu \mathrm{g} / \mu \mathrm{l})$ for G-types was heated at $65 \mathrm{oC}$ for 10 minutes and $4 \mu 1$ of $2.5 \mathrm{mM}$ dNTPs, $10 \mu 1$ of $5 \mathrm{x}$ RT buffer, $1 \mu 1$ of MMLV reverse transcriptase enzyme $(10 \mathrm{U} / \mu \mathrm{l})$, and $4 \mu 1$ DEPC-treated water were added. To produce the complementary (cDNA), the total mixture was heated at $42^{\circ} \mathrm{C}$ for $1 \mathrm{~h}$, followed by $37^{\circ} \mathrm{C}$ for $30 \mathrm{~min}$ then finally $95^{\circ} \mathrm{C}$ for $5 \mathrm{~min}$ to inhibit $\mathrm{RT}$ enzyme.

\section{G-genotyping}

Amplifying of a VP7 gene was carried osut using two steps according to protocol described previously by Iturriza Gomara. ${ }^{19}$ Briefly, the first round was carried out in a final volume $50 \mu \mathrm{l}$ consisting of 5 of cDNA mixed with $10 \mu \mathrm{l}$ of M-MLV $5 \mathrm{X}$ reaction buffer, $4 \mu 1$ of $25 \mathrm{mM} \mathrm{MgCl} 2,4 \mu 1$ of $10 \mathrm{mM}$ dNTPs, $0.25 \mu 1$ of $5 \mathrm{U} / \mathrm{ml}$ Go Taq DNA polymerase (Promega, USA) and $1 \mu 1$ of 25 pmol of each forward primer VP7-F and reverse primer VP7-R (Table 1), 24.75 $\mu 1$ DEPC-treated water. The PCR condition was carried out at $95^{\circ} \mathrm{C}$ for $5 \mathrm{~min}$, followed by 35 cycles at $95^{\circ} \mathrm{C}$ for $1 \mathrm{~min}, 52^{\circ} \mathrm{C}$ for $1 \mathrm{~min}, 72^{\circ} \mathrm{C}$ for $1 \mathrm{~min}$ and then $72^{\circ} \mathrm{C}$ for $10 \mathrm{~min}$ as a final extension. The second round VP7 multiplex was prepared in $50 \mu 1$ total volume containing a $2.5 \mu 1$ of the first round product as a template was mixed with $1 \mu 1$ of each G type-specific primer G1, G2, G3, G4, G8, G9 (Table 1), $10 \mu 1$ of M-MLV 5X reaction buffer, $4 \mu 1$ of $25 \mathrm{mM} \mathrm{MgCl} 2,4 \mu 1$ of $10 \mathrm{mM}$ dNTPs, $0.25 \mu 1$ of $5 \mathrm{U} / \mathrm{ml}$ Go Taq DNA polymerase (Promega, USA), $23 \mu 1 \mathrm{DEPC}$-treated water. The total mixture was subjected to $95^{\circ} \mathrm{C}$ for $5 \mathrm{~min}$ followed by 30 cycles at $94^{\circ} \mathrm{C}$ for $1 \mathrm{~min}, 42^{\circ} \mathrm{C}$ for $2 \mathrm{~min}$, $72^{\circ} \mathrm{C}$ for $1 \mathrm{~min}$ and then a final extension of $72^{\circ} \mathrm{C}$ for $10 \mathrm{~min}$.

Table I Oligonucleotide primer for G typing (VP7) of rotavirus.

\begin{tabular}{|c|c|c|c|c|c|}
\hline \multirow[b]{2}{*}{ Primer } & & \multicolumn{4}{|c|}{ Product } \\
\hline & & Sequence (5-3) & $\begin{array}{l}\text { Size } \\
\text { (bp) }\end{array}$ & $\begin{array}{c}\text { nt. } \\
\text { Position }\end{array}$ & References \\
\hline \multirow{5}{*}{$\begin{array}{l}\text { First } \\
\text { Round }\end{array}$} & VP7-F & ATGTATGGTATTGAATATACCAC & & $5|-7|$ & 2 \\
\hline & VP7-R & TGCCACCATTTTTTCC & & $914-932$ & \\
\hline & G3 & ACGAACTCAACACGAGAGG & 682 & $250-269$ & \\
\hline & G9 & CTTGATGTGACTAYAAAATAC & 179 & 757-776 & \\
\hline & GI0 & ATGTCAGACTACARbATACTGG & 266 & 666-687 & \\
\hline \multirow{4}{*}{$\begin{array}{l}\text { Second } \\
\text { Round }\end{array}$} & G8 & GTCACACCATTTGTAAATTCG & 754 & $178-198$ & \\
\hline & G4 & CGTTTCTGGTGAGGAGTTG & 452 & $480-499$ & \\
\hline & G2 & CAATGATATTAACACATTTTCTGTG & 521 & 4||$-435$ & 21 \\
\hline & GI & CAAGTACTCAAATCAATGATGG & 618 & $314-335$ & \\
\hline
\end{tabular}

\section{Nucleotide sequencing}

The PCR amplicons of most common G-genotype were selected and purified with Qiagen purification kit (Qiagen, Germany), according to the manufacture's guidelines. Using the primers used in the amplification of VP7 in the first round, the purified amplicons were sequenced directly by automated DNA sequence. The produced sequences were compared with available RV sequences in GenBank database.

\section{Results}

\section{Detection of rotavirus and its correlation to age and gender}

Of the 198 samples tested, RV antigens were found in 56(28.3\%) samples. The highest rates of RV gastroenteritis were detected in male $(35 / 56 ; 61.4 \%)$ than in female $(21 / 56 ; 37.5 \%)$. RV gastroenteritis cases were occurred in all different age groups of children, but the majority of RV cases were observed in children aged less than 12 months, accounting for $64.3 \%$ of all rotavirus cases (Figure 1).

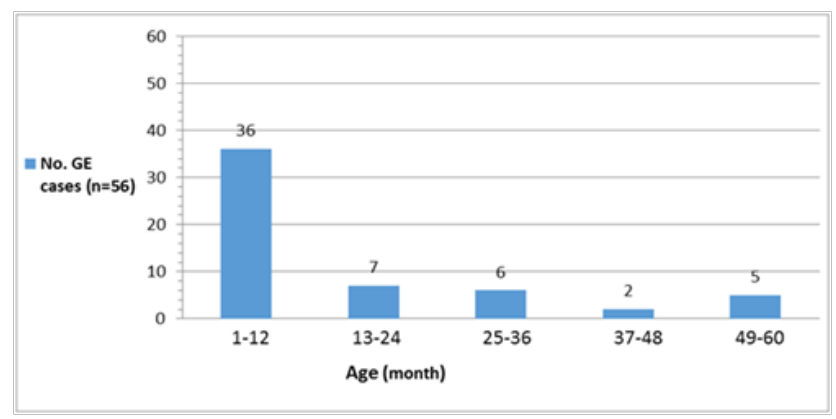

Figure I Age distribution of rotaviruses gastroenteritis from April20I5 to March 2016.

\section{Seasonal distribution}

As shown in Figure 2, RV gastroenteritis was occurred throughout the year, but the frequency of RV among patients was detected in April 2015 (10/56; 17.8\%), followed by March 2016 (11/56; 19.6\%), November 2015 (8/56; 14.3\%). July 2015, December 2015, January 2016 had the same RV gastroenteritis cases with 6/56 (10.7\%). The lowest RVGE cases was found in September 2015 (2/56; $3.6 \%)$, October 2015 (2/56; $3.6 \%)$, and August 2015 (1/56; 1.8\%). During the period from May to June 2015, RV gastroenteritis was not detected.

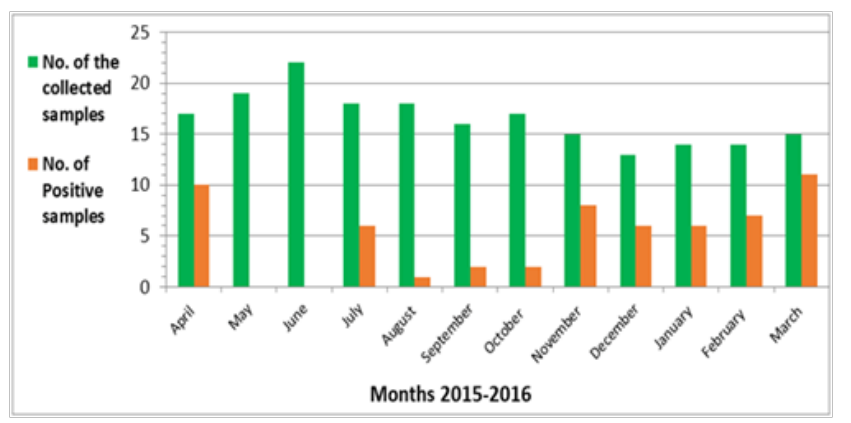

Figure 2 Monthly distribution of rotaviruses gastroenteritis from April 2015 to March 2016.

\section{Rotavirus genotyping}

G genotyping was performed on all RV positive samples ( $\mathrm{n}=56)$ 
by using semi-nested multiplex RT-PCR (Figure 3). G3 was the most prevalent in the population $(10 / 56 ; 17.8 \%)$, followed by G1 $(3 / 56$; $5.3 \%)$, G9 (3/56; 5.3\%), and G10 (3/56; 5.3\%), then G4 $(1 / 56 ; 1.8)$. The most circulating mixed $\mathrm{G}$ types were $\mathrm{G} 1+\mathrm{G} 3+\mathrm{G} 8(10 / 56 ; 17.8 \%)$, followed by G3+G8 $(1 / 56 ; 1.8)$. G1, G3, G9 types were observed separately and in mixed infection whereas G8 type was detected only in mixed infections. The genotype G2 was not found in this study.

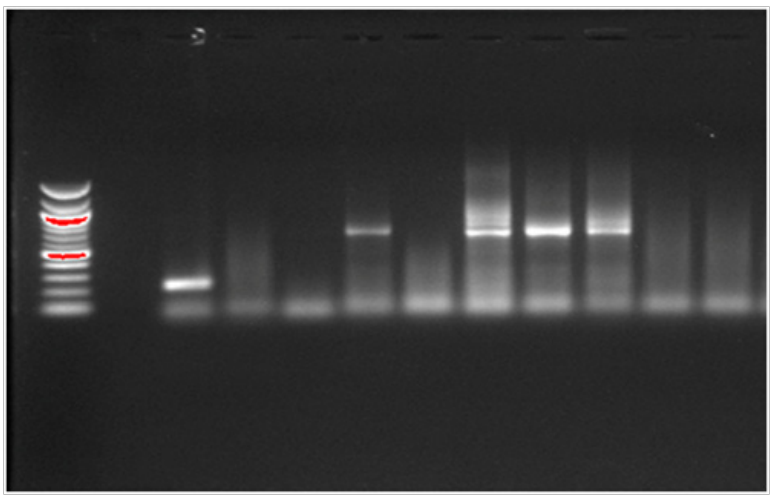

Figure 3 G types of rotavirus detected by semi-nested multiplex RT-PCR;

Lanes I: 12,000 bp molecular weight marker; Lane 2: Negative control; Lanes 3-12, samples: Lane 3: Genotype GI0; Lane 6: Genotype G3; Lane 8: Mixed genotypes (G3+G8); Lane 9: Genotype G3; Lane 10: Mixed genotypes (G3+G8); Lanes 4,5,7, and II are negative RV.

\section{Sequence and phylogenetic analysis}

Nucleotide sequence of the Egyptian G3 isolate showed 99\% nucleotide identity with rotavirus G3 isolate from Turkey and 98\% nucleotide identities with rotavirus G3 isolates from Italy and China.

\section{Discussion}

Rotavirus is the most common etiological agent of non-bacterial severe diarrhea in children, worldwide. This study was conducted to investigate the epidemiology of rotavirus infection among hospitalized and non-hospitalized children with acute diarrhea during 2015/2016 in greater Cairo. A total of 198 diarrheal specimens were tested by ELISA for rotavirus antigen and 56(28.3\%) were positive. This finding is within the range (11-76.9\%) previously detected in Egypt ${ }^{22-29}$ and in other countries (19-93.3\%), including the Middle East and North Africa. ${ }^{30-40}$ The variation in prevalence rates may be attributed to different conditions which may have affected the detection rates. For example, in other studies there were differences in the number of tested samples, season of sample collection, and the sampling methods. The occurrence of the group A Rotavirus was higher in the first 12 months of life (36\%) than in the other age groups, as was observed in previous studies in developing countries ${ }^{22-41}$ This finding may be explained by decline of maternal antibodies with immature immune systems which protect the newborns from pathogens during the firstmonths of life. ${ }^{42}$ In the current research, of the 56 characterized $\mathrm{G}$ types, G3 was the most circulating rotavirus strain. This finding is similar to other previous results from Egypt and Tunisia during the periods August 2011 to August 2012 and June 2009 to 31 May 2011, respectively. ${ }^{29-43} \mathrm{G} 3$ genotype was also the most prevalent rotavirus genotype during the periods, August 2001 to July 2003 and June 2006 and February 2008 in China. ${ }^{44,45}$ Otherwise, two studies from Egypt and Iraq demonstrated that G2 rotavirus was the most common rotavirus strain during the periods, March 2006 to February 2007 and January 2008 and December 2008, respectively. ${ }^{26-46}$ However, G2 was not detected in the current survey, suggesting that G3 strains became the dominant during the latter period. In the present research, G1, G4, G8, G9, and G10 have been identified in 5.3\%, 1.8\%, 5.3\%, 5.3\% of all positive specimens, respectively. El-Senousy and El-Mahdy, ${ }^{47}$ reported that G1 was the most circulating genotype in the Egyptian environment during the period, October 2006 to September 2007. Other epidemiological studies from the Middle East and North Africa, including Tunisia, Saudi Arabia, Iraq, Morocco, Turkey, Libya, and Iran have reported that G1, G9 are the most common rotavirus G types. ${ }^{30-55}$ Also, in the present epidemiological study, the genotype G8 was not observed individually but in mixed infections with $\mathrm{G} 1 /$ G3. Notably, the multiple infections of G1/G3/G8 and G3/G8 are reported for the first time in Egypt. Mixed infections with more than rotavirus strain might implies frequent contamination of water bodies with rotavirus strains, and could promote generation of new rotavirus serotypes through re assortment. Therefore, the efficacy of rotavirus vaccines should be continually investigated.

\section{Conclusion}

Our data suggest that the rotavirus still the important cause of gastroenteritis among children less than 5years of age. Moreover, RotaTeq vaccine containing G3 rotavirus is more suitable for the current status in Egypt to prevent rotavirus infection in infants and children.

\section{Acknowledgement}

None.

\section{Conflict of Interest}

None.

\section{Funding}

None.

\section{References}

1. Buttery JP, Kirkwood C. Rotavirus vaccines in developed countries. Curr Opin Infect Dis. 2007;20(3):253-258.

2. Parashar UD, Steele D, Neuzil K, et al. Progress with rotavirus vaccines: summary of the Tenth International Rotavirus Symposium. Expert Rev Vaccines. 2013;12(2):113-117.

3. Tate JE, Burton AH, Boschi-Pinto C, et al. 2008 estimate of worldwide rotavirus-associated mortality in children younger than 5 years before the introduction of universal rotavirus vaccination programmes: a systematic review and meta-analysis. Lancet Infect Dis. 2012;12(2):136-141.

4. Centers for Disease Control and Prevention. Prevention of rotavirus gastroenteritis among infants and children. MMWR - Morbidity \& Mortality Weekly Report. 2006;55(RR-12):1-13.

5. Dennehy PH, Nelson SM, Crowley BA, et al. Detection of rotavirus RNA in hospital air samples by polymerase chain reaction (PCR). Pediatric Research. 1998;43(Suppl 2):143A.

6. Matthijnssens J, De Grazia S, Piessens J, et al. Multiple reassortmen and interspecies transmission events contribute to the diversity of feline, canine and feline/canine-like human group A rotavirus strains. Infect Genet Evol. 2011;11(6):1396-1406.

7. Papp H, Matthijnssens J, Martella V, et al. Global distribution of group A rotavirus strains in horses: a systematic review. Vaccine. 2013;31(48):5627-5633. 
8. Esona MD, Geyer A, Banyai K, et al. Novel human rotavirus genotype G5P[7] from child with diarrhea, Cameroon. Emerg Infect Dis. 2009;15(1):83-86.

9. Gentsch JR, Laird AR, Bielfelt B, et al. Serotype diversity and reassortment between human and animal rotavirus strains: implications for rotavirus vaccine programs. J Infect Dis. 2005;192(Suppl 1):S146-S159.

10. Matthijnssens J, Potgieter CA, Ciarlet M, et al. Are human P[14] rotavirus strains the result of interspecies transmissions from sheep or other ungulates that belong to the mammalian order Artiodactyla? J Virol. 2009;83(7):2917-2929.

11. Malek MA, Teleb N, Abu-Elyazeed R, et al. The epidemiology of rotavirus diarrhea in countries in the Eastern Mediterranean Region. $J$ Infect Dis. 2010;202(Suppl):S12-S22.

12. Fang ZY, Yang H, Qi J, et al. Diversity of rotavirus strains among children with acute diarrhea in China: 1998-2000 surveillance study. J Clin Microbiol. 2002;40(5):1875-1878.

13. Steele AD, Ivanoff B. Rotavirus strains circulating in Africa during 19961999: emergence of G9 strains and P[6] strains. Vaccine. 2003;21(56):361-367.

14. Gentsch JR, Glass RI, Woods P, et al. Identification of group A rotavirus gene 4 types by polymerase chain reaction. J Clin Microbiol. 1992;30(6):1365-1373

15. Santos N, Hoshino Y. Global distribution of rotavirus serotypes/genotypes and its implication for the development and implementation of an effective rotavirus vaccine. Rev Med Virol. 2005;15(1):29-56.

16. Tate JE, Parashar UD. Rotavirus vaccines in routine use. Clin Infect Dis. 2014;59(9):1291-1301

17. Parez N, Giaquinto C, Du Roure C, et al. Rotavirus vaccination in Europe: drivers and barriers. Lancet Infect. 2014;14(5):416-425.

18. Eing BR, May G, Baumeister HG, et al. Evaluation of two enzyme immunoassays for detection of human rotaviruses in fecal specimens. $J$ Clin Microbiol. 2001;39(12):4532-4534.

19. Iturriza Gomara M, Kang G, Gray J. Rotavirus genotyping: keeping up with an evolving population of human rotaviruses. $J$ Clin Virol. 2004;31(4):259-265.

20. Iturriza Gomara M, Isherwood B, Desselberger U, et al. Reassortment in vivo: driving force for diversity of human rotavirus strains isolated in the United Kingdom between 1995 and 1999. J Virol. 2001;75(8):3696-3705.

21. Gouvea V, Glass RI, Woods P, et al. Polymerase chain reaction amplification and typing of rotavirus nucleic acid from stool specimens. $J$ Clin Microbiol. 199028(2):276-282.

22. Hashem S, Shoman AS, Mohamed FA. Isolation and Molecular Genotyping of Group A Rotavirus Strains Circulating among Egyptian Infants and Children. Egyptian Journal of Medical Microbiology. 2012;21(3):11-20.

23. Ibrahim SB, El-Bialy AA, Mohammed MS, et al. Detection of Rotavirus in children with acute gastroenteritis in Zagazig University Hospitals in Egypt. Electron physician. 2015;7(5):1227-1233.

24. El-Shabrawi M, Salem M, Abou Zekri M, et al. The burden of different pathogens in acute diarrhoeal episodes among a cohort of Egyptian children less thanfive years old. Prz Gastroenterol. 2015;10(3):173-180.

25. El-Senousy WM, Ragab AM, Handak EM. Prevalence of Rotaviruses Groups A and C in Egyptian Children and Aquatic Environment. Food Environ Virol. 2015;7(2): 132-141.

26. Kamel AH, Ali MA, El-Nady HG, et al. Predominance and circulation of enteric viruses in the region of Greater Cairo, Egypt. J Clin Microbiol. 2009;47(4):1037-1045.
27. Matson DO, Abdel-Messih IA, Schlett CD, et al. Rotavirus genotypes among hospitalized children in Egypt, 2000-2002. J Infect Dis. 2010;202,Suppl:S263-S265.

28. Merwad A, Abdallah F, Saber T. Close relationship of group A rotaviruses between bovine and human based onVP7 gene sequence in Egypt. Pakistan Veterinary Journal. 2014;34(3):391-393.

29. Shoeib AR, Hull JJ, Jiang B. Rotavirus G and P types in children with acute diarrhea in Cairo, Egypt, 2011-2012. J Egypt Public Health Assoc. 2015;90(3):121-124.

30. Abugalia M, Cuevas L, Kirby A, et al. Clinical features of molecular epidemiology of rotavirus and norovirus infections Libyan children. $J$ Med Virol. 2011;83(10):1849-1856.

31. Abdul-Ridha NA, Hasan Sh, Salman DA. Comparison study between Enzyme-linked immunosorbant assay and rapid latex agglutination test for the diagnosis of Rotavirus in human. Diyala Journal for Pure sciences. 2015;11(1):82-95.

32. Al-Badani A, Al-Areqi L, Majily A, et al. Rotavirus Diarrhea among Children in Taiz, Yemen: Prevalence-Risk Factors and Detection of Genotypes. Int J Pediatr. 2014:928529.

33. Artiran S, Atalay A, Gokahmetoglu S, et al. Investigation of Rotavirus with Various Methods in Children with Acute Gastroenteritis and Determination of Its Molecular Epidemiology in Kayseri Province, Turkey. J Clin Lab Anal. 2017;31(2).

34. Benhafid M, Rguig A, Trivedi T, et al. Monitoring of rotavirus vaccination in Morocco: establishing the baseline burden of rotavirus disease. Vaccine. 2012;30(46):6515-6520.

35. Kirby A, Al-Eryani A, Al-Sonboli N, et al. Rotavirus and norovirus infections in children in Sana'a, Yemen. Trop Med Int Health. 2011;16(6):680-684.

36. Modaress S, Rahbarimanesh AA, Edalat R, et al. Human Rotavirus Genotypes Detection among Hospitalized Children, A study in Tehran, Iran. Arch Iran Med. 2011;14(1):39-45.

37. Moussa A, Ben Hadj Fredj M, Fodha I, et al. Distribution of rotavirus VP7 and VP4 genotypes circulating in Tunisia from 2009 to 2014: Emergence of the genotype G12. J Med Microbiol. 2016;65(9):1028-1037.

38. Musawi MA, Zainaldeen $\mathrm{H}$, Shafi F, et al. Rotavirus gastroenteritis in children under 5 years in the Kingdom of Bahrain: hospital-based surveillance. Clin Epidemiol. 2017;5:269-275.

39. Obied OE. Characterization of human rotavirus subgroups and serotypes in children under five with acute gastroenteritis in a Saudi Hospital. J Family Community Med. 2011;18(1):22-25.

40. Salem K, Bdour S, Zeller M, et al. Genotypes of rotavirus strains circulating in Amman, Jordan, in 2006/07 and their significance for the potential effectiveness of future rotavirus vaccination. Arch Virol. 2011;156(9):1543-1550.

41. El Qazoui M, Oumzil H, Baassi L, et al. Rotavirus and norovirus infections among acute gastroenteritis children in Morocco. BMC Infect Dis. 2014;14:300.

42. Edwards KM. Maternal antibodies and infant immune responses to vaccines. Vaccine. 2015;33(47):6469-6472.

43. Soltani MS, Salah AB, BouaneneI, et al. Epidemiology and medical cost of hospitalization due to rotavirus gastroenteritis among children under 5 years of age in the central-east of Tunisia. East Mediterr Health J. 2015;21(8):584-590.

44. Wang YH, Kobayashi N, Zhou X, et al. Phylogenetic analysis of rotaviruses with predominant $\mathrm{G} 3$ and emerging $\mathrm{G} 9$ genotypes from adults and children in Wuhan, China. J Med Virol. 2009;81(2):382-389. 
45. Fang ZY, Wang B, Kilgore PE, et al. Sentinel hospital surveillance for rotavirus diarrhea in the People's Republic of China, August 2001-July 2003. J Infect Dis. 2005;192(Suppl 1):S94-S99.

46. Ahmed S, Klena J, Albana A, et al. Characterization of human rotaviruses circulating in Iraq in 2008: atypical G8 and high prevalence of P[6] strains. Infect Genet Evol. 2013;16:212-217.

47. E1-Senousy WM, El-Mahdy EM. Detection and genotyping of rotaviruses in water treatment plants of El-Dakahlia Governorate. Egyptian Journal of Biotechnology. 2009;31:25-34.

48. Abood WS, Al-Juboury AS, Al-Rodhan AM. The molecular epidemiology of rotavirus strains causing gastroenteritis in infant in the region of $\mathrm{Mid}$ Iraq. AL-Qadisiya Journal of Vet Med Sci. 2013;12(1):121-127.

49. Aly M, Al Khairy A, Al Johani S, et al. Unusual rotavirus genotypes among children with acute diarrhea in Saudi Arabia. BMC Infect Dis. 2015;15:192.

50. Chouikha A, Fodha I, Noomen S, et al. Group A rotavirus strains circulating in the Eastern Center of Tunisia during a ten-year period (1995-2004). J Med Virol. 2007;79(7):1002-1008.
51. Kargar M, Najafi A, Zandi K, et al. Genotypic distribution of rotavirus strains causing severe gastroenteritis in children under 5 years old in Borazjan, Iran. African Journal of Microbiology Research. 2011;5(19):2936-2941.

52. Kargar M, Zare M, Najafi A. Molecular Epidemiology of Rotavirus Strains Circulating among Children with Gastroenteritis in Iran. Iran J Pediatr. 2012;22(1):63-69.

53. Khalil M, Azhar E, Kao M, et al. Gastroenteritis attributable to rotavirus in hospitalized Saudi Arabian children in the period 2007-2008. Clin Epidemiol. 2015;7:129-137.

54. Tapisiz A, Karahan ZC, Ciftci E, et al; Changing Patterns of Rotavirus Genotypes in Turkey. Curr Microbiol. 2011;63(6):517-522.

55. Trabelsi A, Fodha I, Chouikha A, et al. Rotavirus strain diversity in the centre coast of Tunisia from 2000 through 2003. J Infect Dis. 2010;202,Suppl:S252-S257. 